Check for updates

Cite this: RSC Adv., 2019, 9, 38174

Received 16th October 2019

Accepted 12th November 2019

DOI: $10.1039 / c 9 r a 08477 k$

rsc.li/rsc-advances

\section{Carbon quantum dots as a fluorophore for "inner filter effect" detection of metronidazole in pharmaceutical preparations}

\author{
Jianghong Tang, (D) * Yaheng Zhang, Yuhai Liu, Dan Liu, (D) Hengfei Qin (D) \\ and Ning Lian
}

\begin{abstract}
With houttuynia cordata as carbon source, photoluminescent carbon quantum dots (CDs) were obtained via a one-step hydrothermal procedure. The absorption band of metronidazole (MNZ, maximum absorption wavelength at $319 \mathrm{~nm}$ ) can well overlap with the excitation bands of CDs (maximum excitation wavelength at $320 \mathrm{~nm}$ ). A fluorescent approach has been developed for detection of MNZ based on the inner filter effect (IFE), in which as-prepared CDs act as an IFE fluorophore and the MNZ as an IFE absorber. We have investigated the mechanism of quenching the fluorescence of CDs and found that the IFE leads to an exponential decay in fluorescence intensity of CDs with increasing concentration of $M N Z$, but showed a good linear relationship $\left(R^{2}=0.9930\right)$ between $\ln \left(F_{0} / F\right)$ with the concentration of MNZ in the range of $3.3 \times 10^{-6}$ to $2.4 \times 10^{-4} \mathrm{~mol} \mathrm{~L}^{-1}$. Due to the absence of surface modification of the CDs or establishing any covalent linking between the absorber (MNZ) and the fluorophore (CDs), the developed method is simple, rapid, low-cost and less time-consuming. Meanwhile, it possesses a higher sensitivity, wider linear range, and satisfactory selectivity and has potential application for detection of MNZ in pharmaceutical preparations.
\end{abstract}

\section{Introduction}

Metronidazole (MNZ), chemically 1-(2-hydroxyethyl)-2-methyl-5nitroimidazole, is a synthetic nitroimidazole derivative with broad-spectrum anti-microbial properties. ${ }^{1}$ It has been widely used for antiprotozoal, antiamebic and antibacterial drugs, and is generally effective in the treatment of trichomoniasis, giardiasis, and amoebiasis diseases. ${ }^{2-4}$ It has also been added to fish and poultry feed to eliminate parasites ${ }^{5}$ or promote weight gain..$^{6,7}$ Due to its low price and efficient treatment of bacterial infections, many commercial companies still illegally use MNZ as an additive in cosmetic materials. ${ }^{8}$ Long term use of MNZ drugs will lead to its accumulation in the human body, and some toxic reactions including seizures, peripheral neuropathy, and cerebellar ataxia, can occur which may pose health risks to humans. ${ }^{9}$ Although there is not enough evidence to confirm its carcinogenic effect on humans, many countries have banned MNZ use in the feed of animals. ${ }^{\mathbf{1 0}}$ Thus, its determination can be of great importance.

Several quantitative analytical methods have been reported to detect the concentration of MNZ in different matrices, such as ultraviolet spectrophotometry, ${ }^{\mathbf{1 1}, 12}$ fluorescence spectroscopy, ${ }^{13,14}$ gas chromatography, ${ }^{15}$ high-performance liquid chromatography, ${ }^{\mathbf{1 6}}$ immunoassay, ${ }^{\mathbf{1 7}}$ solid phase extraction, ${ }^{\mathbf{1 8}}$

School of Chemistry and Environmental Engineering, Jiangsu University of Technology, Changzhou 213001, China. E-mail: tjh01@jsut.edu.cn electrochemical sensor. ${ }^{\mathbf{1 9 - 2 1}}$ However, spectrophotometric methods have some drawbacks such as requirement of long time heating, the use of nonaqueous systems, narrow range of determination, stability of the colored product formed, etc. ${ }^{11,20}$ HPLC method requires a long time involving gradient elution using expensive solvents. ${ }^{20}$ The nitro group in MNZ structure, as the active center for electrochemical sensing, has shown poor reproducibility and sensitivity at conventional electrodes. ${ }^{10}$ In general, modification of electrodes surfaces with suitable materials to improve the sensitivity and stability. Regarding some disadvantages of these reported methods, it is very significant to develop an alternative facile method with high selectivity and sensitivity for MNZ determination.

In recent years, fluorescent carbon dots (CDs) received great attention for their advantageous features, such as excellent aqueous dispersibility, special optical characteristics, low toxicity, good biocompatibility and good photostability. ${ }^{22,23}$ To date, CDs as a new type of emerging fluorescent nanoma terials, have been reported for their promising applications in metal cations and anions analysis, ${ }^{24,25}$ photocatalysis, ${ }^{26}$ biological imaging, ${ }^{27,28}$ biosensors, ${ }^{29-32}$ environmental analysis, ${ }^{33,34}$ small molecules detection. ${ }^{35-37}$ In view of carbon sources, the synthetic strategy are used to prepare carbon dots mainly refers to three kinds of classes, combustion/strong acid oxidizing raw carbon materials, ${ }^{26}$ hydrothermal process of biomass, ${ }^{38,39}$ carbonization of small molecule carbon precursors with 
different passivation reagents, achieving simultaneous fabrication and surface functionalization of CDs. ${ }^{\mathbf{2 4 , 4 0}}$ It is worth note that hydrothermal process of biomass is a simple, cost-effective and environmentally friendly method, and the number of bioresources that can be used for the preparation of carbon dots is more than that of other two types of carbon materials. ${ }^{39}$

The inner filter effect (IFE), one of the non-irradiation energy conversions, is owing to the absorption of the excitation and/or emission radiation of fluorophores by absorbers in the detection system..$^{41-43}$ Only the absorption spectra of the absorbers overlap with the excitation and/or emission bands of the fluorophore, the IFE would generate effectively. It is a useful strategy for conversion the analytical absorption signals into fluorescence signals. The absorption of the excitation of fluorophores by absorbers is called primary inner filter effect (pIFE), and secondary inner filter effect (SIFE) refers to the absorption of emission light. ${ }^{44}$ There is no chemical covalent interaction between the absorber and the fluorophore in the detection system. Therefore, implementing the IFE process is facile, simple and inexpensive.

Houttuynia cordata is a perennial plant belonging to the saururaceae family, which is a traditional medicinal plant in eastern Asia. It possesses very promising antiviral properties and is used as antipyretic, detoxicant, anti-ulcer remedy anti-inflammatory agent. It contains many chemical components consisting of $\mathrm{C}, \mathrm{H}, \mathrm{O}$ three kinds of elements, such as decanoy acetaldehyde $\left(\mathrm{C}_{12} \mathrm{H}_{22} \mathrm{O}_{2}\right)$, lauraldehyde $\left(\mathrm{C}_{12} \mathrm{H}_{24} \mathrm{O}\right)$, a-pinene $\left(\mathrm{C}_{10} \mathrm{H}_{16}\right)$, methyl nonyl ketone $\left(\mathrm{C}_{11} \mathrm{H}_{22} \mathrm{O}\right)$, $\beta$-sitosterol $\left(\mathrm{C}_{29} \mathrm{H}_{50} \mathrm{O}\right)$, camphene $\left(\mathrm{C}_{10} \mathrm{H}_{16}\right)$, stearic acid $\left(\mathrm{C}_{18} \mathrm{H}_{36} \mathrm{O}_{2}\right)$, chlorogenic acid $\left(\mathrm{C}_{16} \mathrm{H}_{18} \mathrm{O}_{9}\right)$, quercetin $\left(\mathrm{C}_{15} \mathrm{H}_{10} \mathrm{O}_{7}\right),{ }^{45,46}$ and so on.

In the present work, eco-friendly CDs were prepared using houttuynia cordata as the carbon source through the hydrothermal process. Due to the absorption band of MNZ can well overlap with excitation light of the prepared CDs, a fluorescent assay has been developed for detecting of MNZ based on IFE (Fig. 1). ${ }^{41}$

\section{Experiment section}

\subsection{Materials}

Houttuynia cordata was purchased from Zhongcheng Pharmacy (Changzhou, China). MNZ (Sun Chemical Technology Shanghai Co., Ltd) was dissolved in water to prepare a $1.00 \times 10^{-2} \mathrm{~mol} \mathrm{~L}^{-1}$ stock solution. All chemicals were of analytic grade purity and used in this work without further purification. Ultrapure water

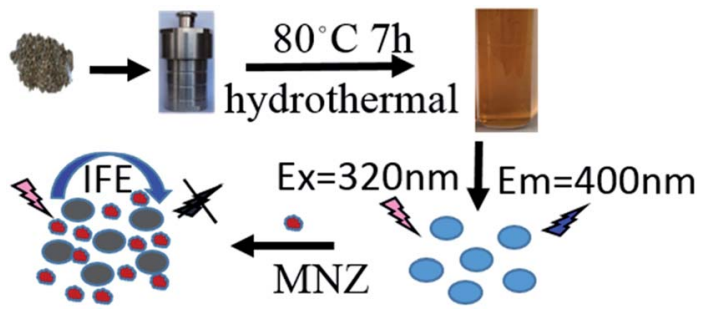

Fig. 1 Schematic illustration of the synthesis process of CDs and detection of MNZ via IFE. prepared from a Milli-Q water purification system (Millipore, Billerica, MA, USA) were used throughout the experiment.

\subsection{Apparatus and methods}

All fluorescence spectra and intensities were recorded on a Cary Eclipse fluorescence spectrometer (Varian, USA), excitation and emission bandwidths set on 5 and $10 \mathrm{~nm}$, respectively. Fluorescence lifetime was measured with FluoroMax+ (America) instruments by using an excitation wavelength of $375 \mathrm{~nm}$. X-ray photoelectron spectroscopy (XPS) measurements were carried out with ESCALAB 250Xi (America) X-ray photoelectron spectrometer. An electronic thermo regulating Water-bath (NTT-2100, EYELA, Japan) was used to control the temperature. A UV-1800PC Spectrophotometer (Shanghai, China) was used for acquiring the UV-vis absorption spectra in a given wavelength range. Fourier transform-infrared spectrometry (FTIR) was recorded at room temperature with a Nicolet IR200 Spectrometer (America) ranging from 650 to $4000 \mathrm{~cm}^{-1}$. The microstructures and size of CDs were acquired on transmission electron microscopy (JEM2100 , Japan) with a $200 \mathrm{kV}$ accelerating voltage.

\subsection{Preparation of fluorescence CDs}

CDs were prepared through a simple hydrothermal method with the houttuynia cordata as the carbon source. At first, $0.5 \mathrm{~g}$ of houttuynia cordata pieces was dispersed in $30 \mathrm{~mL}$ of ultrapure water with sonication for 10 minutes. Then, it was transferred into a $50 \mathrm{~mL}$ Teflon-equipped stainless steel autoclave, sealed, heated to $80{ }^{\circ} \mathrm{C}$ for $7 \mathrm{~h}$ in an air drying oven, and then cooled to room temperature naturally. To remove indispersible matters, the resultant brown yellow mixture was centrifuged at $15000 \mathrm{rpm}$ for $20 \mathrm{~min}$. The supernatant containing CDs was collected and filtered through a $0.22 \mu \mathrm{m}$ filter membrane. The obtained suspension of carbon dots was stored at $4{ }^{\circ} \mathrm{C}$ for further characterization and applications.

\subsection{General procedure for fluorescence titration}

$2.5 \mathrm{~mL}$ CDs solution and $0.5 \mathrm{~mL}$ Tris buffer solution $(\mathrm{pH}=8.0)$ was taken into $1.0 \mathrm{~cm}$ quartz cuvette. The mixture was titrated by successive additions of MNZ working solution (the final of MNZ concentrations range from $3.3 \times 10^{-6}$ to $2.4 \times 10^{-4} \mathrm{~mol} \mathrm{~L}^{-1}$ ). The drug was added from a concentrated stock solution so that volume increment was negligible. Titrations were done manually by using trace syringes, and the fluorescence signal was gained at excitation and emission wavelength of 320 and $440 \mathrm{~nm}$. The experiments of the quenching mechanism were performed at three temperatures $(298,308$, and $318 \mathrm{~K})$. Fluorescence titration can be used for the detection of real sample. ${ }^{47}$

\subsection{Real sample preparation}

Take 10 tablets MNZ tables and grind fine, about $70 \mathrm{mg}$ of the powder was dissolved in water and diluted to $100.0 \mathrm{~mL}$. Filter them with dry filter paper and discard the initial portion, the filtrate was collected and used for analytical determinations. 


\section{Results and discussion}

\subsection{Characterization of the CDs}

The size and morphology of the CDs were characterized by TEM. From the Fig. 2A and B, it can be observed that the CDs display excellent monodispersity in aqueous solution and a quasispherical irregular morphology. Their diameters are not of uniform size distributed in the range of 6-10 $\mathrm{nm}$ with an average diameter of $7.5 \pm 2.6 \mathrm{~nm}$ (based on statistical analysis of 100 dots). The HRTEM image (inset of Fig. 2B) demonstrates clear lattice fringes with an interplanar spacing of $0.27 \mathrm{~nm}$, which is similar to other previously reported CDs. ${ }^{24}$

The FT-IR spectroscopy was employed to identify the surface functional groups of the synthesized CDs. As shown in Fig. 2C, the broad absorption band at $3370 \mathrm{~cm}^{-1}$ and peak at $1764 \mathrm{~cm}^{-1}$ were assigned to the stretching vibration of $-\mathrm{OH}$ and $-\mathrm{COOH}$ respectively. These indicated that there were many hydroxyl and carboxyl groups on CDs surface, which enabled the prepared CDs to exhibit excellent water solubility. The peaks at 1658 and $1342 \mathrm{~cm}^{-1}$ were attributed to the bending vibrations of $\mathrm{C}=\mathrm{C}$ and $\mathrm{C}-\mathrm{O}$, the asymmetric and symmetric stretching vibrations of $\mathrm{C}-\mathrm{O}-\mathrm{C}$ appeared at 1127 and $996 \mathrm{~cm}^{-1}$. The FT-IR analysis indicated that CDs have been successfully synthesized through the hydrothermal process.

The UV-visible absorption spectrum of CDs in aqueous solution was investigated. As shown in Fig. 2D, the prepared CDs depicted two absorption peaks at the wavelengths 205 and $275 \mathrm{~nm}$. The absorption peak at $205 \mathrm{~nm}$ corresponded to the
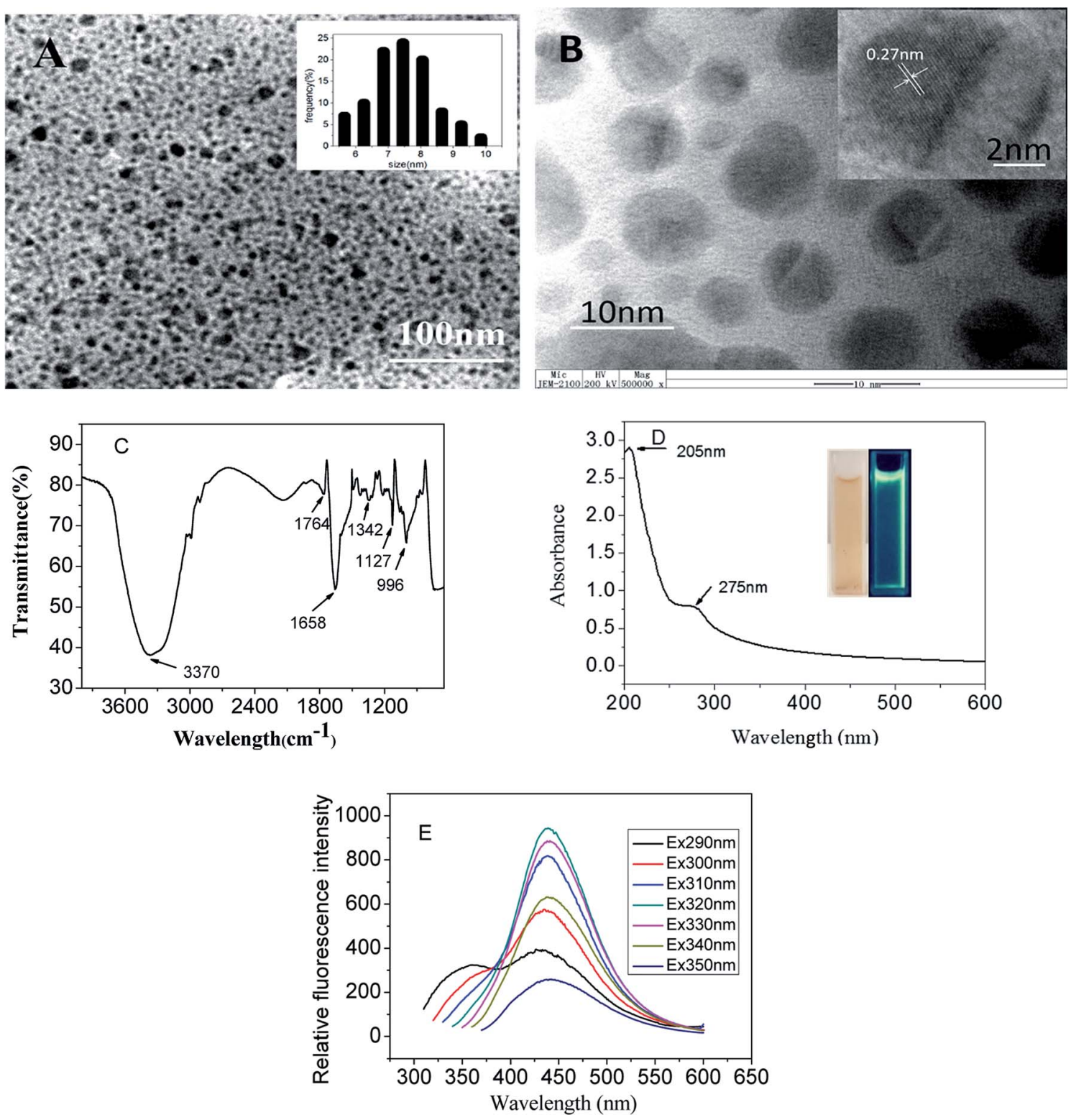

Fig. 2 (A) $100 \mathrm{~nm}$ and (B) $10 \mathrm{~nm}$ TEM images of the CDs, Insets in (A) and (B): size distribution and HRTEM of the CDs; (C) FT-IR spectrum of the CDs; (D) UV-vis absorption spectrum of CDs. The insets are the photographs of CDs in aqueous solution under room light (left) and UV light (365 nm, right); (E) emission spectra of the CDs under different excitation wavelengths. 
formation of carboxyl group chromophores, and peak at $275 \mathrm{~nm}$ ascribed to $\pi-\pi^{*}$ transition of $\mathrm{C}=\mathrm{C}$ bond. ${ }^{24}$ Furthermore, the color of the CDs aqueous solution was pale yellow under ambient daylight but exhibited strong cyan emission under the $365 \mathrm{~nm}$ ultraviolet radiation (Fig. 2D, inset).

The excitation dependent emission spectra of prepared CDs were obtained under the excitation wavelength from 290 to $350 \mathrm{~nm}$ (Fig. 2E). It was observed that with the excitation wavelength increased from 290 to $310 \mathrm{~nm}$, the maximum emission peak position of CDs exhibited slightly red-shift. While the excitation wavelength was over $310 \mathrm{~nm}$, the maximum emission wavelength remained constant, and the fluorescence intensity was firstly increased and subsequently decreased. The maximum fluorescence intensity at $440 \mathrm{~nm}$ corresponded to the excitation wavelength of $320 \mathrm{~nm}$. Such excitation wavelength-dependent fluorescence behavior was ascribed to the existence of several surface state emissive trap as well as the different morphologies of CDs. ${ }^{24}$ The fluorescence quantum yield of prepared CDs was calculated to be $10.5 \%$ using quinine sulfate as the standard (54\%).

XPS was performed to explore the composition and the valent state of the prepared CDs. In the survey spectrum (Fig. 3a) there were two dominant peaks at $284.6 \mathrm{eV}(\mathrm{C} 1 \mathrm{~s})$, and $532.1 \mathrm{eV}$ (O 1s) which can be attributed to $\mathrm{C} 1 \mathrm{~s}$, and $\mathrm{O}$ 1s. The highresolution $\mathrm{C}$ 1s spectrum (Fig. 3b) exhibits three distinct carbon states of $\mathrm{C}=\mathrm{C} / \mathrm{C}-\mathrm{C}$ with a binding energy at $284.7 \mathrm{eV}$, $\mathrm{C}=\mathrm{O}$ at $287.5 \mathrm{eV}$ and $\mathrm{O}=\mathrm{C}-\mathrm{OH}$ at $289.1 \mathrm{eV}^{24,25}$ which in accord with the FT-IR analysis. These results suggested that there are apparent hydrophilic functional groups on the surface of the asprepared CDs.

\subsection{Analysis of quenching mechanism}

The efficient IEF would occur when the absorption band of the absorber (quenchers) possesses a good spectral overlap with the excitation and/or emission bands of the fluorophore. As observed in Fig. 4, the maximum absorption wavelength of MNZ aqueous solution is $319 \mathrm{~nm}$, and the prepared CDs has maximum excitation wavelength at $320 \mathrm{~nm}$, showing absorption band of MNZ almost completely overlapping with the excitation bands of CDs. Owing to MNZ shield the excitation light for CDs, increasing the concentration of MNZ could be successfully converted to fluorescence quenching of CDs. ${ }^{42,48}$

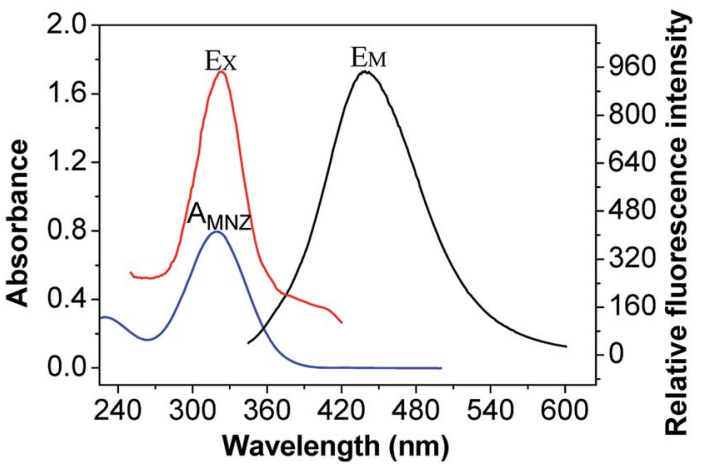

Fig. 4 Fluorescence excitation (EX) and emission (EM) spectra of CDs and UV-vis absorption spectrum of MNZ ( $\left.A_{M N Z}\right)$.

The efficiency of quenching of a fluorophore species by a quencher species could be described by the Stern-Volmer equation.

$$
F_{0} / F=1+K_{\mathrm{Q}} \tau_{0}[Q]=1+K_{\mathrm{SV}}[Q]
$$

where $F_{0}$ and $F$ are the fluorescence intensities of as-prepared CDs in the absence and presence of MNZ, respectively, $[Q]$ is the concentration of MNZ solution, $K_{\mathrm{SV}}$ is the Stern-Volmer quenching constant, $K_{\mathrm{Q}}$ is the bimolecular quenching rate constant and $\tau_{0}$ is the lifetime of the fluorophore in the absence of quencher (for most biomolecules $\tau_{0}$ is about $10^{-8} \mathrm{~s}$ ). ${ }^{47}$

Quenching can be induced by different mechanisms, such as dynamic quenching, static quenching, inner filter effect, and so on. Dynamic quenching process based on the excitedstate fluorophore return to the ground state by the collision action with the quencher, static quenching arose from the formation of a nonfluorescent ground-state complex between fluorophore and quencher, IFE would generate when the quenchers absorb the excitation and/or emission of the fluorophore in the detection system. The quenching constant increased with increasing temperature for dynamic quenching while it decreased with increasing temperature for static quenching. The process of IFE does not belong to the static or dynamic quenching process, ${ }^{49}$ the quenching constant of IFE was no temperature-dependent.
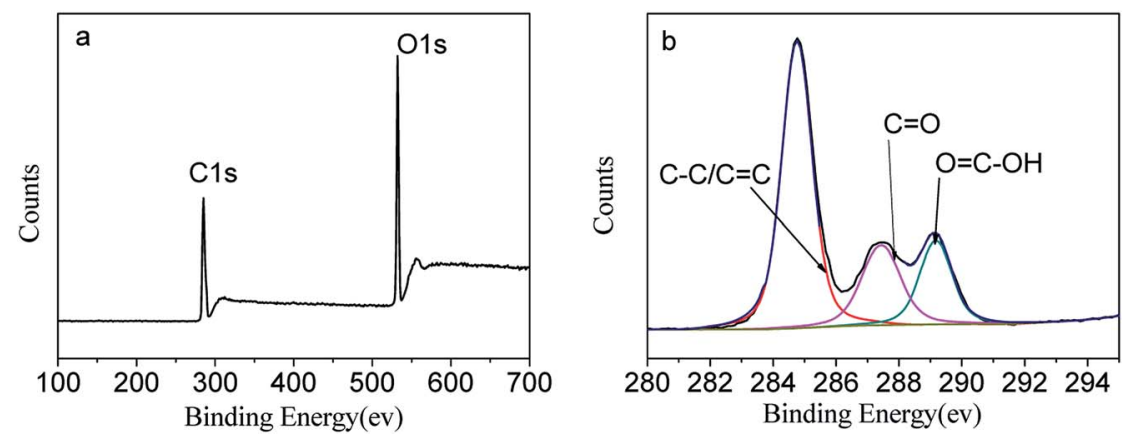

Fig. 3 XPS survey spectrum of the obtained CDs (a) and the enlarged regions for $C$ is (b). 
In order to further clarify the fluorescence quenching mechanism, the interaction of MNZ with CDs was studied by fluorescence titration at three different temperatures. The quenching constant for the interaction of CDs and MNZ were listed in Table 1 . As Table 1 showed, the quenching constant display a very small change. It can be seen in Fig. 5 that the Stern-Volmer plots were a linear relationship between $F_{0} / F$ and concentration of MNZ, but the slopes were not temperaturedependent, suggesting that the quenching mechanism neither dynamic nor static quenching, the possible quenching mechanism is IFE.

Moreover, the fluorescence decays were measured to clarify the quenching mechanism, because the fluorescence lifetime of fluorophore is almost constant in IFE quenching process. As shown in Fig. 6, the data were found to be fit well to a threeexponential function, and the average fluorescence lifetime of CDs and CDs-MNZ were 3.531 and 3.526 ns, respectively. The fact that there is no change in the fluorescence lifetime of CDs before and after MNZ is added suggests that the mechanism of the quenching process probably is IEF.

Practically, IFE is an attenuation of the excitation light or absorption of emission radiation by the quencher in solution. Because the IFE does not belong to the static or dynamic quenching. In this process, there is no new substance to form, the absorption peaks of the fluorophore or quencher would not change. ${ }^{44}$ Fig. 7 shows the UV absorption spectra of CDs, MNZ and the mixture solutions of CDs and MNZ. When using ultrapure water as reference solution, it can be seen that the

Table 1 The quenching constant for the interaction of CDs and metronidazole at $\mathrm{pH} 8.0$ measured by fluorimetric titration

\begin{tabular}{llll}
\hline Temperatures $(\mathrm{K})$ & $K_{\mathrm{SV}}{ }^{a}\left(\mathrm{~L} \mathrm{~mol}^{-1}\right)$ & $R^{2}$ & $\mathrm{SD}\left(\times 10^{4}\right)$ \\
\hline 298 & $3.0 \times 10^{4}$ & 0.9974 & 0.0425 \\
308 & $3.2 \times 10^{4}$ & 0.9917 & 0.0386 \\
318 & $3.1 \times 10^{4}$ & 0.9944 & 0.0518
\end{tabular}

${ }^{a}$ Mean of three determinations.

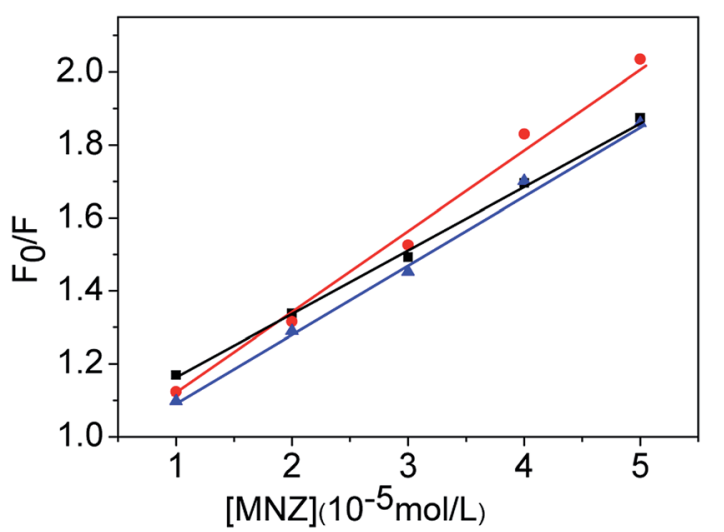

Fig. 5 Stern-Volmer plots for the MNZ quenching of CDs fluorescence at three different temperatures $(\mathbf{a} 298 \mathrm{~K}, \bullet 308 \mathrm{~K}, \Delta 318 \mathrm{~K}), \mathrm{pH}=$ 8.0, $\lambda_{\mathrm{ex}}=320 \mathrm{~nm}, \lambda_{\mathrm{em}}=440 \mathrm{~nm}$.

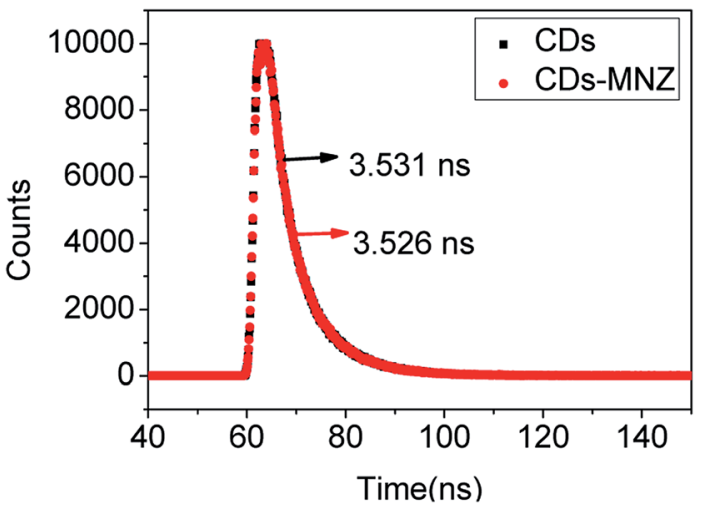

Fig. 6 Fluorescence decay curves of CDs and CDs-MNZ with emission monitored at $440 \mathrm{~nm}$ and excitations at $375 \mathrm{~nm}$.

absorption peaks of CDs, MNZ and the mixture of CDs and MNZ were different (Fig. 7a, b and c). However, with the same concentration CDs as reference solution, the absorption spectrum of the mixture containing CDs and MNZ (Fig. 7d) coincides with the spectrum of MNZ (Fig. 7b, with ultrapure water as reference) in the wavelength range of 240-600 $\mathrm{nm}$. This case demonstrated that the absorption spectrum of the mixture is the sum of the absorbance of two component, CDs and MNZ. These evidences indicated there is no new substance to form between CDs and MNZ, and MNZ quenching CDs fluorescence is not static and dynamic, but IFE.

\subsection{Effects of $\mathrm{pH}$ value}

It is well known that both the size and surface states are crucial in the optical properties of CDs. Due to the protonation or deprotonation of the functional groups on the surface of CDs in acid and alkali solution, different $\mathrm{pH}$ values might affect the fluorescence intensity of CDs. In order to seek an optimal $\mathrm{pH}$ value for sensitive determination of $\mathrm{MNZ}$, the effect of $\mathrm{pH}$ on the fluorescence intensity of the prepared CDs was investigated.

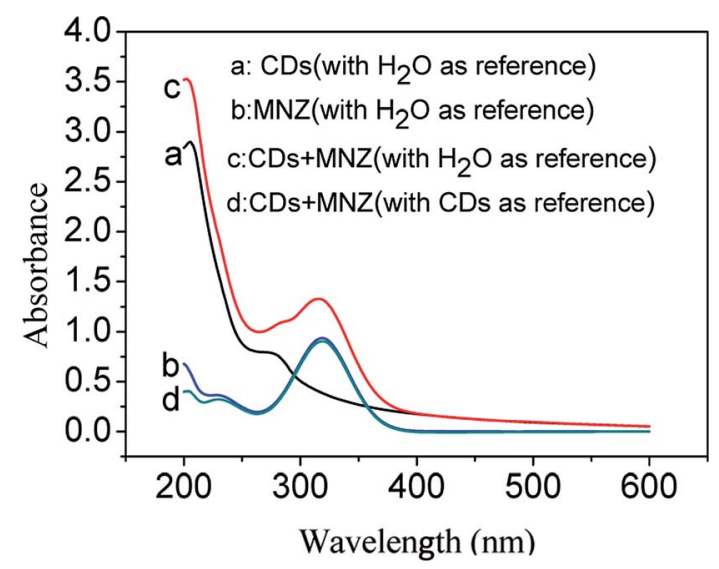

Fig. 7 UV-vis absorption spectra of CDs, MNZ, and a mixture containing CDs and MNZ. (a) CDs solution, (b) MNZ solution $(1 \times$ $10^{-4} \mathrm{~mol} \mathrm{~L}^{-1}$ ), (c) CDs + MNZ (with ultrapure water as reference), (d) $\mathrm{CDs}+\mathrm{MNZ}$ (with CDs as reference). $\mathrm{pH}=8.0$. 


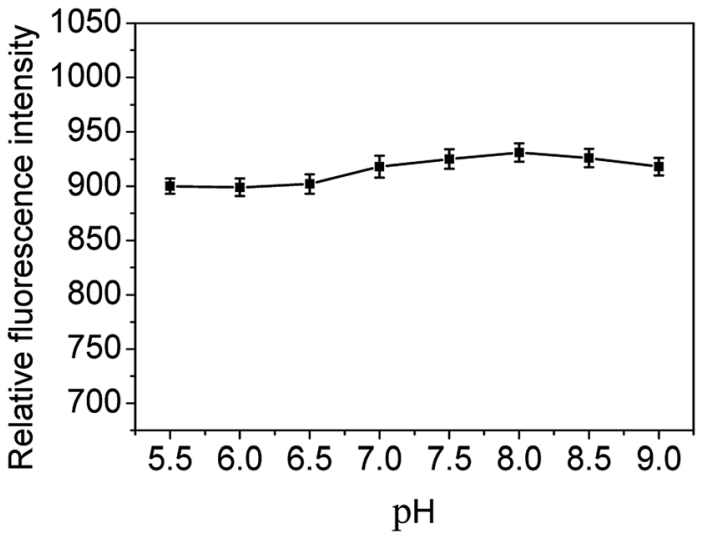

Fig. $8 \mathrm{pH}$ effect on fluorescence intensity of the CDs.

The results (Fig. 8) showed that there is a slight variation of the fluorescence intensity of CDs in the $\mathrm{pH}$ from 5.5 to 9.0, and the fluorescence intensity reached its maximal value at $\mathrm{pH}$ 8.0. On the other hand, the nitrogen atoms on the imidazole ring of a MNZ molecule are easy to be protonated at low $\mathrm{pH}$. With the decrease of $\mathrm{pH}$, the maximum absorption wavelength of $\mathrm{MNZ}$

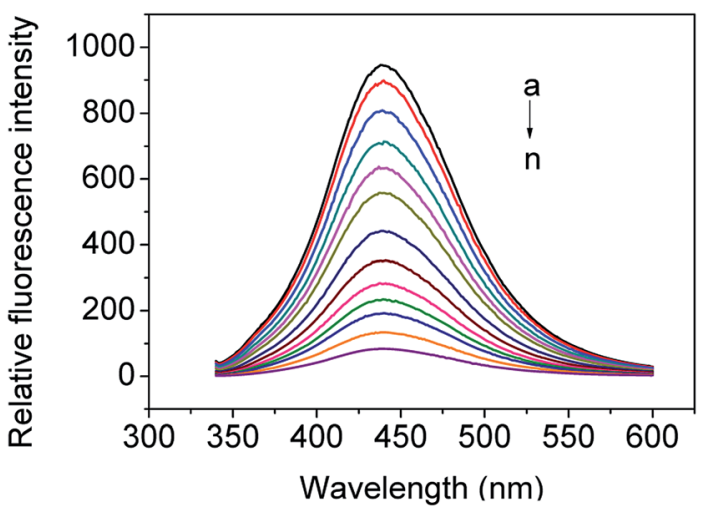

Fig. 9 Fluorescence emission spectra of CDs in the presence of MNZ. $(\mathrm{a}-\mathrm{m})$ as-prepared CDs solution in the presence of $0,0.33,1.0,2.0$, $3.0,4.0,6.0,8.0,10.0,12.0,14.0,18.0$, and $24.0 \times 10^{-5} \mathrm{~mol} \mathrm{~L}^{-1} \mathrm{MNZ}$, respectively. $\mathrm{pH}=8.0, \lambda_{\mathrm{ex}}=320 \mathrm{~nm}$. solution shifts towards the short wavelength, ${ }^{12,50}$ and this will weaken the absorption of MNZ on the excitation light of CDs, which also leads to the reduction of quenching efficiency. So the Tris-HCl buffer solution was chosen to keep $\mathrm{pH}$ the value of 8.0 in the present work.

\subsection{Quantitative determination of MNZ}

Fig. 9 shows the fluorescence emission spectra of as-prepared CDs solution in the absence and presence of MNZ (the final range of $\mathrm{MNZ}$ concentrations were from $3.3 \times 10^{-6}$ to $2.4 \times$ $10^{-4} \mathrm{~mol} \mathrm{~L}^{-1}$ ). It can be seen that CDs had a strong fluorescence emission band at $440 \mathrm{~nm}$. The emission intensity of the CDs solution decreased gradually with the increase of concentration of MNZ step by step, implying that adding MNZ effectively quenched the fluorescence of the CDs. According to the experimental data, over 91\% (suppressed efficiency $E=1-F / F_{0}$ ) fluorescence intensity of CDs was quenched when the final concentration of MNZ increased to $2.4 \times 10^{-4} \mathrm{~mol} \mathrm{~L}^{-1}$.

According to the above experimental results, the plot of $F_{0} / F$ versus the concentration of MNZ displayed an exponential decay in the range of $3.3 \times 10^{-6}$ to $2.4 \times 10^{-4} \mathrm{~mol} \mathrm{~L}^{-1}, 51$ but exhibited a linear relationship in the range of $3.3 \times 10^{-6}$ to $5 \times$ $10^{-5}$ mol L ${ }^{-1}$ with $R^{2}=0.9974$, as shown Fig. 10A. The limit of detection (LOD) was calculated to be $1.2 \times 10^{-7} \mathrm{~mol} \mathrm{~L}^{-1}$ using the equation $\mathrm{LOD}=3 \sigma / s$, where $\sigma$ is the standard deviation of the blank signals $(n=11)$, and $s$ is the slope of the linear calibration curve. Meanwhile, the plot of exponential decay in Fig. 10A showed a good linear relationship $\left(R^{2}=0.9930\right)$ between $\ln \left(F_{0} / F\right)$ and the concentration of MNZ in the range of $3.3 \times 10^{-6}$ to $2.4 \times$ $10^{-4} \mathrm{~mol} \mathrm{~L}^{-1}$ (Fig. 10B). The determination of MNZ in real samples can be calculated by the following linear equation:

$$
\ln \left(F_{0} / F\right)=0.01016[\mathrm{MNZ}]+0.11998
$$

where [MNZ] is the concentration of MNZ, $F_{0}$ and $F$ represent the observed fluorescence intensity of CDs in the absence and presence of MNZ, respectively. Compared with other reported methods, as shown in Table 2. The present method has lower LOD and wide linear response range for determining the MNZ concentration.
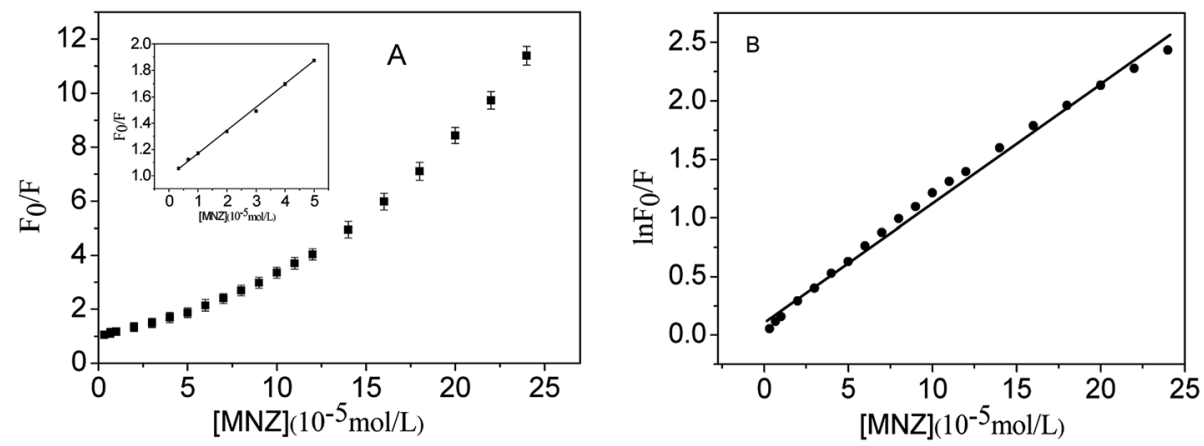

Fig. 10 (A) The Stern-Volmer plot of CDs fluorescence quenched by MNZ. (B) Fitting curve of the plot in panel (A). $\lambda_{\mathrm{ex}}=320 \mathrm{~nm}, \lambda_{\mathrm{em}}=440 \mathrm{~nm}$. $\mathrm{pH}=8.0$. 
Table 2 Comparison of the proposed method with other reported methods for the determination of MNZ

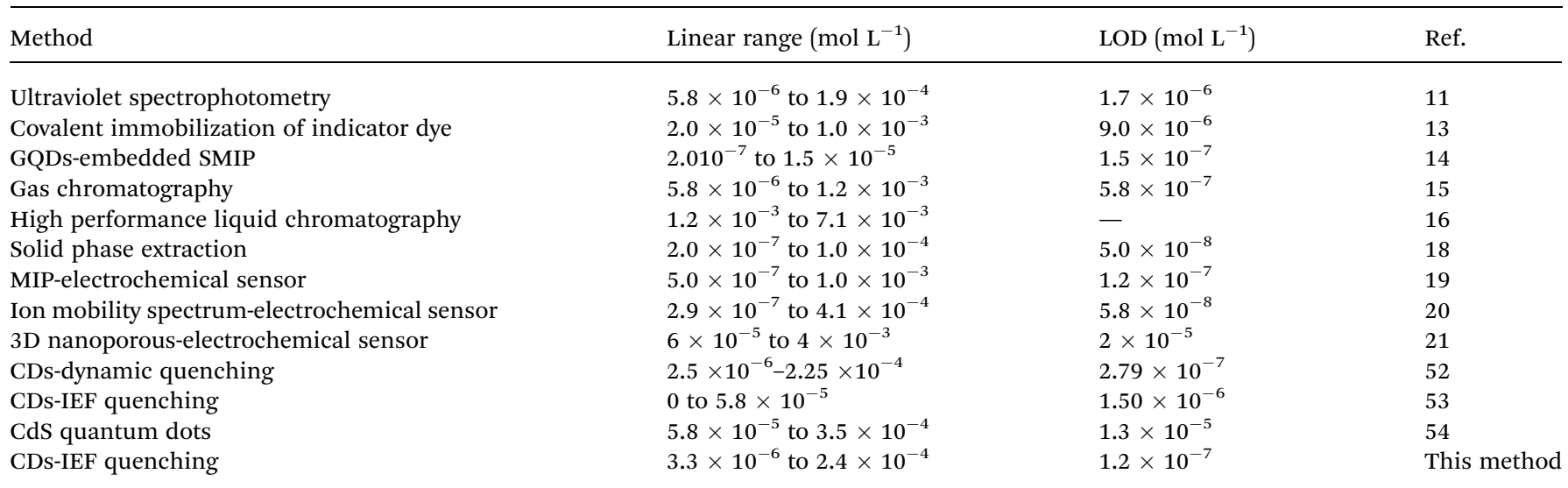

\subsection{Effects of coexisting substances}

To evaluate the selectivity of the proposed MNZ detection method, the effect of some potential interferents was investigated. We tested the responses of the CDs solution ( $\mathrm{pH}$ 8.0) containing 1.0 $\times 10^{-4} \mathrm{~mol} \mathrm{~L}^{-1} \mathrm{MNZ}$ without and with an interfering material, respectively. The results suggested that relative fluorescence intensity change caused by common ions except $\mathrm{Fe}^{3+}$ and some pharmaceutical species were less than $5.0 \%$ (Table 3 ). Therefore, this method has a sufficient selectivity for MNZ, making it practicable for practical applications in analyzing pharmaceutical preparations.

\subsection{Analytical applications}

The proposed method was used for determinations of MNZ content in commercial MNZ tablets and to test the recovery from the spiked tablets. The preparation of sample solutions, as discussed in the experimental section, analyzed using fluorescence titration by linear eqn (2). The content of MNZ in the tablets (labelled value $0.250 \mathrm{~g}$ per tablet) determined by the present method was compared with those assayed by UVvis method, ${ }^{12}$ which suggests that there is a good agreement between the quantitative data from the two methods. The intra- and inter-day results obtained are listed in Table 4. The recoveries of for the detection of spiked MNZ in pharmaceutical tablets in intra- and inter-day were 101.5-104.9\% and 101.1-103.4\%. Therefore, these results revealed that this method showed good precision and accuracy and has potential application for the detecting of MNZ in pharmaceutical preparations.

Table 3 Effect of different species to the determination of MNZ using prepared CDs solution ${ }^{a}$

\begin{tabular}{llc}
\hline & & $\begin{array}{l}\text { Relative fluorescence intensity change } \\
\left(F_{2}-F_{1} / F_{1}\right)(\%)\end{array}$ \\
\hline $\mathrm{KCl}$ & Concentration $\left(\mathrm{mol} \mathrm{L}^{-1}\right)$ & 0.52 \\
$\mathrm{NaCl}$ & $1.0 \times 10^{-3}$ & 1.12 \\
$\mathrm{NH}_{4} \mathrm{Cl}$ & $1.0 \times 10^{-3}$ & 3.81 \\
$\mathrm{NaNO}_{3}$ & $1.0 \times 10^{-3}$ & 2.10 \\
$\mathrm{Na}_{2} \mathrm{CO}_{3}$ & $1.0 \times 10^{-3}$ & 2.89 \\
$\mathrm{CaCl}_{2}$ & $1.0 \times 10^{-3}$ & 4.45 \\
$\mathrm{MgSO}_{4}$ & $1.0 \times 10^{-3}$ & 3.47 \\
$\mathrm{AlCl}_{3}$ & $1.0 \times 10^{-3}$ & 2.10 \\
$\mathrm{Fe}\left(\mathrm{NO}_{3}\right)_{3}$ & $1.0 \times 10^{-3}$ & 13.32 \\
ZnCl$_{2}$ & $1.0 \times 10^{-3}$ & 1.44 \\
Glucose $_{5}$ & $1.0 \times 10^{-3}$ & 4.52 \\
5 -Hydroxymethylfurfual & $1.0 \times 10^{-3}$ & 1.83 \\
Tryptophan & $1.0 \times 10^{-3}$ & 2.16 \\
Urea & $1.0 \times 10^{-3}$ & 3.20 \\
Lidocaine & $1.0 \times 10^{-3}$ & 2.61 \\
Erythromycin & $1.0 \times 10^{-3}$ & 3.21 \\
Diphenhydramine & $1.0 \times 10^{-3}$ & 4.01 \\
Chlorphenirammum & $1.0 \times 10^{-3}$ & 3.20 \\
Sulfaguanidine & $1.0 \times 10^{-3}$ & 2.98
\end{tabular}

${ }^{a} F_{1}$ and $F_{2}$ are fluorescence intensities CDs detection solution (pH 8.0) exposed to $1.0 \times 10^{-4} \mathrm{~mol} \mathrm{~L}^{-1} \mathrm{MNZ}$, without and with coexisting substance, respectively. 
Table 4 Determination and recovery tests of MNZ in pharmaceutical tablets $(n=5)$

\begin{tabular}{|c|c|c|c|c|c|c|c|c|c|}
\hline \multirow[b]{2}{*}{$\begin{array}{l}\text { Detected } \\
(\mu \mathrm{M})\end{array}$} & \multirow[b]{2}{*}{$\begin{array}{l}\text { Spiked } \\
(\mu \mathrm{M})\end{array}$} & \multicolumn{3}{|c|}{ Intra-day results } & \multicolumn{3}{|c|}{ Inter-day results } & \multirow{2}{*}{$\begin{array}{l}\text { Present } \\
\text { method } \\
\text { (g per tablet) }\end{array}$} & \multirow{2}{*}{$\begin{array}{l}\text { UV-vis } \\
\text { method } \\
\text { (g per tablet) }\end{array}$} \\
\hline & & $\begin{array}{l}\text { Total found } \\
(\mu \mathrm{M})\end{array}$ & $\begin{array}{l}\text { Recovery } \\
(\%)\end{array}$ & $\begin{array}{l}\mathrm{RSD}(\%) \\
n=5\end{array}$ & $\begin{array}{l}\text { Total found } \\
(\mu \mathrm{M})\end{array}$ & $\begin{array}{l}\text { Recovery } \\
(\%)\end{array}$ & $\begin{array}{l}\mathrm{RSD}(\%) \\
n=5\end{array}$ & & \\
\hline \multirow[t]{3}{*}{$30.36 \pm 0.31$} & 30.00 & $61.82 \pm 0.45$ & 104.9 & 3.6 & $61.38 \pm 0.29$ & 103.4 & 4.2 & $0.252 \pm 0.032$ & $0.255 \pm 0.021$ \\
\hline & 60.00 & $91.23 \pm 0.28$ & 101.5 & 2.3 & $91.01 \pm 0.33$ & 101.1 & 3.8 & & \\
\hline & 90.00 & $122.55 \pm 0.51$ & 102.4 & 2.1 & $121.88 \pm 0.61$ & 101.7 & 5.2 & & \\
\hline
\end{tabular}

\section{Conclusion}

Using houttuynia cordata as a carbon source, new CDs were successfully prepared through a one-step hydrothermal method. We have demonstrated a fluorescent approach for detection of MNZ based on IFE, in which as-prepared CDs act as an IFE fluorophore and the MNZ as an IFE absorber. Due to no surface modification of fluorophore (CDs) and covalent bond coupling between absorber (MNZ) and fluorophore, the developed method is facile, rapid, low cost and less time-consuming. The results revealed that this method showed satisfactory selectivity and has potential application for the detecting of MNZ in pharmaceutical preparations.

\section{Conflicts of interest}

The authors declared that they have no conflict of interest.

\section{Acknowledgements}

The authors acknowledge the funding support from National Natural Science Foundation of China (31800495) and Natural Science Foundation of Jiangsu Province (BK20181040).

\section{References}

1 A. M. Jarrad, T. Karoli, A. Debnath, C. Y. Tay, J. X. Huang, G. Kaeslin, A. G. Elliott, Y. Miyamoto, S. Ramu and A. M. Kavanagh, Eur. J. Med. Chem., 2015, 101, 96-102.

2 L. A. Dunn, K. T. Andrews, J. S. Mccarthy, J. M. Wright, T. S. Skinner-Adams, P. Upcroft and J. A. Upcroft, Int. J. Antimicrob. Agents, 2007, 29, 98-102.

3 J. Z. Huang, X. L. Shen, R. L. Wang, Q. Zeng and L. S. Wang, RSC Adv., 2017, 7, 535-542.

4 H. Qureshi, A. Ali, R. Baqai and W. Ahmed, J. Int. Med. Res., 1997, 25, 167-170.

5 H. B. Ammar, M. Brahim, R. Abdelhedi and Y. Samet, Sep. Purif. Technol., 2016, 157, 9-16.

6 Z. Fang, X. Qiu, J. Chen and X. Qiu, Appl. Catal., B, 2010, 100, 221-228.

7 W. Cheng, M. Yang and Y. Y. Xie, Environ. Technol., 2013, 34, 2977-2987.

8 M. Liu, X. Y. Li, J. J. Li, X. M. Su, Z. Y. Wu, P. F. Li, F. H. Lei, X. C. Tan and Z. W. Shi, Anal. Bioanal. Chem., 2015, 407, $3875-3880$.
9 N. Xiao, J. Deng, J. L. Cheng, S. Q. Ju, H. Q. Zhao, J. Xie, D. Qian and J. He, Biosens. Bioelectron., 2016, 81, 54-60.

10 E. Shahnazari-Shahrezaie and A. Nezamzadeh-Ejhieh, RSC Adv., 2017, 7, 14247-14253.

11 P. Nagaraja, K. R. Sunitha, R. A. Vasantha and H. S. Yathirajan, J. Pharm. Biomed. Anal., 2002, 28, 527-535.

12 X. Zhang, L. Q. Tong and L. Y. Zhang, Jiangsu Pharmaceutical and Clinical Research, 2004, 4, 14-15.

13 S. H. Tan, J. H. Jiang, B. N. Yan, G. L. Shen and R. Q. Yu, Anal. Chim. Acta, 2006, 560, 191-196.

14 M. Mehrzad-Samarin, F. Faridbod, A. S. Dezfuli and M. R. Ganjali, Biosens. Bioelectron., 2017, 92, 618-623.

15 J. H. Wang, J. Chromatogr. A, 2001, 918, 435-438.

16 A. Mishal and D. Sober, J. Pharm. Biomed. Anal., 2005, 39, 819-823.

17 C. S. Thompson, I. M. Traynor, T. L. Fodey and S. R. H. Crooks, Anal. Chim. Acta, 2009, 637, 259-264.

18 D. Chen, J. Deng, J. Liang, J. Xie, K. H. Huang and C. H. Hu, Anal. Methods, 2013, 5, 722-728.

19 Y. Gu, X. Y. Yan, C. Li, B. Zheng, Y. R. Li, W. L. Liu, Z. Q. Zhang and M. Yang, Biosens. Bioelectron., 2016, 77, 393-399.

20 M. T. Jafari, B. Rezaei and B. Zaker, Anal. Chem., 2009, 81, 3585-3591.

21 Y. C. Li, Y. Liu, Y. Yang, F. Yu, J. Liu, H. Song, J. Liu, H. Tang, B. C. Ye and Z. P. Sun, ACS Appl. Mater. Interfaces, 2015, 7, 15474-15480.

22 S. L. Hu, Chem. Rec., 2016, 16, 219-230.

23 H. Hamishehkar, B. Ghasemzadeh, A. Naseri, R. Salehi and F. Rasoulzadeh, Spectrochim. Acta, Part A, 2015, 150, 934939.

24 Z. Fu, M. H. Yao, X. Q. Niu and F. L. Cui, Sens. Actuators, B, 2016, 226, 486-494.

25 X. T. Cao, J. Ma, Y. P. Lin, B. X. Yao, F. M. Li, W. Weng and X. C Lin, Spectrochim. Acta, Part A, 2015, 151, 875-880.

26 S. L. Hu, R. X. Tian, L. L. Wu, Q. Zhao, J. L. Yang, J. Liu and S. R. Cao, Chem.-Asian J., 2013, 8, 1035-1041.

27 W. Zhang, R. X. Wang, W. Liu, X. Wang, P. Li, W. Zhang, H. Wang and B. Tang, Chem. Sci., 2018, 9, 721-727.

28 V. Sharma, N. Kaur, P. Tiwari and S. M. Mobin, J. Photochem. Photobiol., B, 2018, 182, 137-145.

29 S. Huang, L. M. Wang, C. S. Huang, J. N. Xie, W. Su, J. R. Sheng and Q. Xiao, Sens. Actuators, B, 2015, 221, 1215-1222. 
30 X. M. Xu, Y. Cen, G. H. Xu, F. D. Wei, M. L. Shi and Q. Hu, Biosens. Bioelectron., 2019, 131, 232-236.

31 S. M. Ardekani, A. Dehghani, P. Ye, K. A. Nguyen and V. G. Gomes, J. Colloid Interface Sci., 2019, 552, 378-387.

32 Q. Yang, J. H. Li, X. Y. Wang, H. Xiong and L. X. Chen, Anal. Chem., 2019, 91, 6561-6568.

33 J. L. Yu, X. Y. Wang, Q. Kang, J. H. Li, D. Z. Shen and L. X. Chen, Environ. Sci.: Nano, 2017, 4, 493-502.

34 X. Y. Wang, J. L. Yu, X. Q. Wu, J. Q. Fu, Q. Kang, D. Z. Shen, J. H. Li and L. X. Chen, Biosens. Bioelectron., 2016, 81, 438444.

35 M. Jahanbakhshi and B. Habibi, Biosens. Bioelectron., 2016, 81, 143-150.

36 H. L. Tao, X. F. Liao, Q. Y. Wu, X. L. Xie, F. X. Zhong, Z. S. Yi, M. Qin and Z. L. Wu, Spectrochim. Acta, Part A, 2016, 153, 268-272.

37 S. L. Yang, L. Wang, L. Zuo, C. Zhao, H. Y. Li and L. Ding, Microchim. Acta, 2019, 186, 652-660.

38 Z. Y. Yan, Z. W. Zhang and J. Q. Chen, Sens. Actuators, B, 2016, 225, 469-473.

39 J. Zhang, L. Dong and S. H. Yu, Sci. Bull., 2015, 60, 785-791.

40 B. B. Campos, M. M. Oliva, R. Contreras-Cáceres, E. Rodriguez-Castellón, J. Jiménez-Jiménez, J. C. G. Esteves da Silva and M. Algarra, J. Colloid Interface Sci., 2016, 465, 165-173.

41 G. L. Li, H. L. Fu, X. J. Chen, P. W. Gong, G. Chen, L. Xia, H. Wang, J. M. You and Y. N. Wu, Anal. Chem., 2016, 88, 2720-2726.
42 S. Khezri, M. Bahram and N. Samadi, Anal. Methods, 2017, 9, 6513-6524.

43 H. Kim, B. I. Lee and S. H. Byeon, Chem. Commun., 2015, 51, 725-728.

44 Q. Gu and J. E. Kenny, Anal. Chem., 2009, 81, 420-426.

45 K. H. Chiow, M. C. Phoon, T. Putti, B. K. H. Tan and V. T. Chow, Asian Pac. J. Trop. Med., 2016, 9, 1-7.

46 Q. G. Ma, R. R. Wei, Z. Q. Wang, W. M. Liu, Z. P. Sang, Y. P. Li and H. C. Huang, J. Ethnopharmacol., 2017, 195, 166-172.

47 J. H. Tang, S. D. Qi and X. G. Chen, J. Mol. Struct., 2005, 779, 87-95.

48 M. Zheng, Z. G. Xie, D. Qu, D. Li, P. Du, X. B. Jing and Z. C. Sun, ACS Appl. Mater. Interfaces, 2013, 5, 13242-13247.

49 F. L. Zu, F. Y. Yan, Z. J. Bai, J. X. Xu, Y. Y. Wang, Y. C. Huang and X. G. Zhou, Microchim. Acta, 2017, 184, 1899-1914.

50 W. H. Liu, Y. Wang, J. H. Tang, G. L. Shen and R. Q. Yu, Anal. Sci., 1998, 14, 547-551.

51 W. Y. Zhai, C. X. Wang, P. Yu, Y. X. Wang and L. Q. Mao, Anal. Chem., 2014, 86, 12206-12213.

52 X. P. Yang, M. X. Liu, Y. R. Yin, F. L. Tang, H. Xu and X. J. Liao, Sensors, 2018, 18, 964-978.

53 J. R. Zhao, X. H. Pan, X. B. Sun, W. Pan, G. F. Yu and J. P. Wang, Luminescence, 2018, 33, 704-712.

54 R. I. El-Bagary, A. A. El-Zaher, E. F. Elkady and A. A. Mandour, Future J. Pharm. Sci., 2018, 4, 185-190. 